\title{
THE DYNAMIC FACILITY LAYOUT PROBLEMS WITH CLOSENESS RATE: A FUZZY DECISION SUPPORT SYSTEM APPROACH
}

\author{
1Betül TURANOĞLU, ${ }^{2}$ Gökay AKKAYA \\ ${ }^{1}$ Ataturk University, Department of Industrial Engineering, Yakutiye, Erzurum, Turkey \\ ${ }^{2}$ Ataturk University, Department of Industrial Engineering, Yakutiye, Erzurum, Turkey \\ 1b.turanoglu@atauni.edu.tr,2gakkaya@atauni.edu.tr
}

(Geliş/Received: 08.02.2017 ; Kabul/Accepted in Revised Form: 30.03.2017 )

\begin{abstract}
One of the most important characteristics of modern manufacturing is the continuous variability of the demand. Today's business w orld should be able to respond to sudden changes in order to survive the competitive environment. The dynamic layout planning that take into account the variability of demand in certain time periods is an example of these studies. The dynamic facility layout problems (DFLP) attempt to balance the handling and transportation costs. In this study, closeness rates between the departments are used as a parameter in DFLP model. In addition, a fuzzy decision system which integrates multiple input types is proposed to determine the closeness rates and an DFLP instance consisting of six departments and five periods is solved. Results obtained for conventional closeness rates and the rates obtained by the offered method are reported. The results indicate the superiority of the offered model over the conventional one.
\end{abstract}

Keywords: Fuzzy decision support system, Fuzzy rule base, Closeness rates, Dynamic facility layout problem

Yakınlık Oranlı Dinamik Yerleşim Düzeni Problemleri: Bir Bulanık Karar Destek Sistemi Yaklaşımı

ÖZ: Modern imalatın en önemli özelliklerinden biri, talebin sürekli değişkenlik göstermesidir. Günümüzün iş dünyası, rekabet ortamında hayatta kalabilmek için ani değişikliklere cevap verebilmelidir. Belli zaman aralıklarında talebin değişkenliğini ele alan dinamik yerleşim planlaması, bu çalışmaların bir örneğidir. Dinamik tesis düzeni problemleri (DYDP) taşıma ve taşıma maliyetlerini dengelemeye çalışmaktadır. Bu çalışmada DYDP modelinde, departmanlar arasındaki yakınlık oranları bir parametre olarak kullanılmıştır. Buna ek olarak, yakınlık oranlarını belirlemek için birkaç girdi türünü entegre eden bulanık bir karar sistemi önerilmiş ve altı bölüm ve beş periyottan oluşan bir DYDP örneği çözülmüştür. Geleneksel yakınlık oranları ve önerilen yöntemle elde edilen oranlar için elde edilen sonuçlar raporlanmıştır. Sonuçlar, önerilen modelin geleneksel model üzerindeki üstünlügüüü göstermektedir.

Anahtar Kelimeler: Bulanık karar destek sistemi, Bulanık kural tabanı, Yakınlık oranları, Dinamik tesis düzeni problemi

\section{INTRODUCTION}

Facility layout problem is one of the complex problems that have been widely studied in the literature. It is about the physical organization of the departments within a facility. The facility can be

DOI: $10.15317 /$ Scitech.2017.90 
described as a machine, a manufacturing cell or an office. A well-designed placement of the facility contributes to the effectiveness of the processes and reduces the total operating expenditures, work-inprocess, idle times, manufacturing lead times, etc. In the other words, facility layout design plays an important role for the productivity of a manufacturing system. The objective of the facility layout problem is to minimize the total cost by placement of the departments (Nourelfath et al., 2007). The effectiveness of layout problems conventionally has been attributed to flow of materials. The material handling cost is commonly used to evaluate alternative layout designs. Hence, the location of facilities in a production system is determined under the criterion of material handling cost minimization (Baykasoğlu and Gindy, 2001). These costs are based on the quantity of material flow and the distance between the facilities (Ulutaş and Islier, 2009).

If the characteristic of the material flows does not change from time to time, the layout problem is said to posses a static nature. In such cases, a single period facility layout problem is solved to minimize total material handling cost. However, in application, companies generally produce in dynamic environments. Due to demand variability, minor changes in the locations of departments or machines may provide some advantages. Dynamic facility layout problems are based on the arrangement of facilities to minimize the sum of material handling and re-layout costs by considering multi periods. Dynamic approach provides more effective layouts to meet the requirements of the changing environments compared to the static layout problems (Ulutaş and Islier, 2009).

If a facility is configured without considering the demand variability, a new facility layout should be determined. The re-layout of the departments may cause some production losses and some indirect costs such as production control, loss of time and training costs. How ever, if the potential gain after changes is large enough, the re-layout is considered as economical and reasonable. In such cases, the planner may be willing to play a game against the nature. In this game, there are chance and decision points. The customer changes his/her preferences, and a new structure of demand occur at the change points. Then, the planner decides whether or not he will change the facility layout in the decision point. This decision should balance the material handling and the re-layout costs. If the re-layout costs are lower than the material handling costs, a new layout can be made (Ulutaş and Islier, 2009).

The assumptions for the DFLP are clarified as follows (Pourvaziri and Naderi, 2014):

- Planning horizon is splited to T period.

- The distances between locations and the material flow between each pair of facilities are known.

- In each time period, each facility should be assigned only one location and one facility can be placed to only one location.

- The objective is to achieved the layout plan which minimizes the sum of the material handling and re-layout costs for all periods.

The static approach may be used in the dynamic environment though there are disadvantages. For instance, a short planning horizon can be used so that the flows are fairly constant during the horizon or a long planning horizon can be used and ignored the changes in flow. The total flow over the planning horizon can be determined by adding the material flows in each period to get the total flow. There will be no re-layout costs, but this may cause in the layout being uneffective throughout the horizon. The dynamic approach corrects these imperfections by striking a balance betw een the material handling and rearrangement costs and planning future layout rearrangements (Balakrishnan and Cheng, 1998).

One of the assumptions of the classical linear programming is the certainty of the parameters. The data often possess a stochastic nature in practice. Therefore, real-life problems can be modeled by using fuzzy numbers representing indefinite numerical data. In this study, the closeness rates between departments have been added to the model of DFLP as a new parameter. Besides, the fuzzy system approach has been proposed to calculate the closeness rates. The conventional closeness rates and the closeness rates which are obtained by the proposed approach have been tested on a DFLP instance with 6 departments and 5 periods. It has been shown that the proposed method produce better results. 
The paper is structured as follows: Quadratic Assignment Problem (QAP) and Dynamic Facility Layout Problem (DFLP) are mentioned in Section 2. Then, the structure of fuzzy decision making system is discussed in Section 3. Section 4 proposes the fuzzy decision making system to calculate the closeness rates and tests the proposed method on an illustrative example. The last section comprises conclusions.

\section{QUADRATIC ASSIGNMENT PROBLEM AND DYNAMIC FACILITY LAYOUT PROBLEM}

The Quadratic Assignment Problem (QAP) is commonly seen in facility location studies. The basic difference between the QAP and the classic assignment problem is that there is interaction between the assignment pairs in the QAP, leading to a non-linear objective function. The QAP is NP-hard as shown implying that finding a polynomial time heuristic solution method is unlikely by Sahni and Gonzales (Sahni and Gonzales, 1976). Indeed, the computational complexity of QAP is such that even instances of size $20 \leq \mathrm{n} \leq 30$ represent a real challenge for the current exact approaches (Benlic and Hao, 2013).

The QAP is initially introduced by Koopmans and Beckman (1957), where the cost of assigning facility $i$ to location $j$ and of facility $k$ to location $l$ is $\mathrm{f}_{i k}$. $\mathrm{d}_{j l}$ with $\mathrm{f}_{i k}$ denoting the material flow per unit time between facilities $i$ and $k$ and $\mathrm{d}_{j l}$ denoting the distance between locations $j$ and $l$. Let $\mathrm{x}_{i j}$ to be 1 if facility $i$ is assigned to location $j$, and 0 otherwise. The formulation of the QAP is as follows:

$$
\begin{array}{ll}
\text { Minimize }= & \sum_{i, j, k, l=1}^{n} f_{i k} d_{j l} x_{i j} x_{k l} \\
\sum_{i=1}^{n} x_{i j}=1, & \forall j \in\{1, \ldots, n\} \\
\sum_{j=1}^{n} x_{i j}=1, & \forall i \in\{1, \ldots, n\} \\
x_{i j} \in\{0,1\} &
\end{array}
$$

DFLP extends the QAP by minimizing the sum of material handling and re-layout costs by arranging the layout for each production period. The mathematical model introduced by Balakrishnan and Cheng is as follows:

$$
\begin{aligned}
& \operatorname{Min} \sum_{t=2}^{T} \sum_{i=1}^{N} \sum_{j=1}^{N} \sum_{l=1}^{N} A_{t i j l} x_{(t-1) i j} x_{t i l}+\sum_{t=1}^{T} \sum_{i=1}^{N} \sum_{j=1}^{N} \sum_{k=1}^{N} \sum_{l=1}^{N} f_{t i k} d_{j l} x_{t i j} x_{t k l} \\
& \sum_{j=1}^{N} x_{t i j}=1, \quad i=1,2, \ldots, N, \quad t=1,2, \ldots, T \\
& \sum_{i=1}^{N} x_{t i j}=1, \quad j=1,2, \ldots, N, \quad t=1,2, \ldots, T \\
& x_{t i j} \in\{0,1\}, \forall i, j, t
\end{aligned}
$$

where $N$ is the number of locations and departments; $T$ denotes the number of periods; $f_{t i k}$ indicates material flow between departments $i$ and $k$ at period $t ; d_{j l}$ stands for the distance between locations $j$ and $l$; and finally $A_{t i j}$ is the re-layout cost of department $i$ from location $j$ to $l$ at period $t$.

Rosenblatt (1986) makes the first attempt to model the DFLP. He proposes a dynamic programming model for solution of the DFLP. Heuristic methods are also used for the DFLP. For instance, Conway and Venkataramanan (1994), Ulutaş and Islier (2009), Mazinani et al. (2013), Pourvaziri and Naderi 
(2014) use genetic algorithm while Kaku and Mazzola (1997) present a tabu search algorithm to solve the DFLP. Balakrishnan et al. (1992) presents solutions for constrained DFLP. Lacksonen and Enscore (1993) examine different mathematical programming approaches. Hirabayashi et al. (1999) propose evolutionary methods for flexible manufacturing systems. Balakrishnan and Cheng (2000) enhance the genetic algorithm presented in the study of Conway and Venkataramanan (1994), Baykasoglu and Gindy (2001) also present a simulated annealing application. Balakrishnan et al. (2003) develop two heuristics that improve Urban's steepest-drop pairw ise interchange heuristic. The first one uses Urban's heuristic to generate solutions of the DFLP. The solutions generated for each forecast window is improved by using a backward-pass pairwise exchange heuristic and the best solution is selected. The second one combines Urban's heuristic with dynamic programming. Besides, Erel et al. (2003) propose a three-phase method to solve the DFLP. In the first phase, a set of "good" layouts are produced by integrating the flow data using a weighting scheme and solving the static facility layout problem for each period. In the second phase, the set of solutions generated in the first stage and dynamic programming is used to produce solutions for the DFLP. In the third phase, the solutions obtained in the second stage are improved using a random drop pairwise swap approach. Baykasoglu et al. (2006) made the first attempt for DFLP with budget constraints. McKendall and Shang (2006) present hybrid ant systems for the DFLP. Moslemipour et al. (2012) review the intelligent approaches for dynamic and robust layout problems. El-Rayes and Said (2009) study a dynamic programming approach for a dynamic site layout. Zouein and Tommelein (1999) solve a dynamic layout planning using a hybrid method. McKendall and Liu (2012) propose new tabu search heuristics for the problem while Sahin et al. (2010) study the DFLP with a budget constraint. Finally, Hosseini et al. (2014) propose a hybrid metaheuristic to solve the DFLP.

Fortenberry and Cox (1985) use the material handling cost as $A_{i j k l}=f_{i k} d_{j l} r_{i k}$ in their study on the static facility layout problem. Here, $f_{i k}$ shows the material flow between departments $i$ and $k$ while $d_{j l}$ shows the distance between locations $j$ and $l$, and $r_{i k}$ is the closeness ratebetween departments $i$ and $k$. We make use of the closeness rate idea but extend it to multiple periods. Parameter $r_{t i k}$ represent the closeness rate between departments $i$ and $k$ in period $t$. As a result, the model is regulated as follows:

$$
\begin{aligned}
& \operatorname{Min} \sum_{t=2}^{T} \sum_{i=1}^{N} \sum_{j=1}^{N} \sum_{l=1}^{N} A_{t i j l} x_{(t-1) i j} x_{t i l}+\sum_{t=1}^{T} \sum_{i=1}^{N} \sum_{j=1}^{N} \sum_{k=1}^{N} \sum_{l=1}^{N} f_{t i k} d_{j l} r_{t i k} x_{t i j} x_{t k l} \\
& \sum_{j=1}^{N} x_{t i j}=1, \quad i=1,2, \ldots, N, \quad t=1,2, \ldots, T \\
& \sum_{i=1}^{N} x_{t i j}=1, \quad j=1,2, \ldots, N, \quad t=1,2, \ldots, T \\
& x_{t i j} \in\{0,1\}, \forall i, j, t
\end{aligned}
$$

\section{THE STRUCTURE OF FUZZY DECISION MAKING SYSTEM}

The word "fuzzy" describe all the information that is vague and deficient about an issue. In a fuzzy environment, researchers cannot directly use the equations derived by conventional methods. Fortunately, the problem at hand can be modeled by the fuzzy approach instead of deterministic programming models. Since the events of the real world is too complex, it is unlikely controlling and modeling of the events. In this case, the methods that can be solved are prefered. The fuzzy decision making system approach can be shown as one of the methods.

Fuzzy set theory is introduced by Zadeh (1965). Accordingly, fuzzy set is defined which permits partial membership. Consequently, the membership of an element is indicated by a number within $[0,1]$ interval. The fuzzy set theory is developed to solve problems having uncertain boundaries. It models 
uncertainties of the real life and has a wide range of the application. The fuzzy set theory is used in many fields such as operations research, management science, artificial intelligence and expert systems.

The first application of fuzzy set theory for the facility layout problems is by Wilhelm et al. (1987). Instead of the traditional closeness rates, proximity significance between each department pair is calculated by an approach what they call as "similarity index". Grobelny $(1987 a, 1987 b, 1988)$ and Raoott and Rakshit $(1991,1993)$ also use the fuzzy method for layout problems. Dweiri (1999)'s the fuzzy approach incorparates Analytic Hierarchy Process (AHP) for determinig the closeness rates. Deb and Bhattacharyya (2005) develop a fuzzy decision support system for the development of facility layout with fixed pickup/drop-off points.

The four main components of a fuzzy decision making system are given below (Altaş, 1999; Deb and Bhattacharyya, 2005; Dweiri, 1999; Şen, 2001):

- Fuzzification: The values of the input and output variables are measured, the range of these values is determined, and converted into natural language (low, very low, high, etc.).

- Knowledge base: The membership functions are described by the experts of the system.

- Fuzzy rule base: "IF-THEN" type of rules logically connecting the input and output variables are created. The structure of the rules should be as "If Ax and Bx, then Cz". The connective 'and' can be considered as the intersection operation in set operations. When the memb ership functions of fuzzy sets are considered, conjunction function "and" determines the minimum value of the input variables' membership values. Therefore, the membership value of output variable ' $z$ ' for each rule is determined as follows:

$$
\mu(z)=\min [\mu(x), \mu(y)]
$$

This expression represents the relationship between $\mathrm{X}$ and $\mathrm{Y}$ spaces and is shown as $Z=X \times Y$ Cartesian product.

All fuzzy set connections between the input and output data should be considered while creating the fuzzy rules. The rule base is a result of these fuzzy rules and so the implied connections. Fuzzy relations are usually illustrated by tables, relationship diagrams and matrix.

- Defuzzification: All the rules created in the fuzzy rule base are converted to a crisp value using a defuzzification method. The structure of the fuzzy decision support system is summarized in Figure 1.

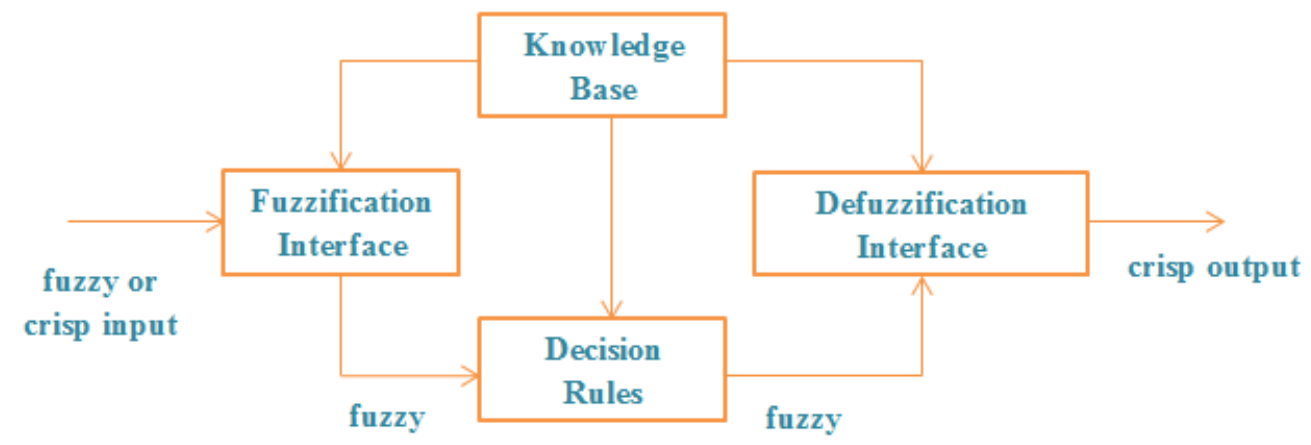

Figure 1. Fuzzy decision making system (Dweiri, 1999)

\section{AN APPLICATION ON AN ILLUSTRATIVE EXAMPLE}

The relationship between departments in a facility is an important factor while designing the facility layout. Some of the most common relationships considered in literature for facility layout problems are (Dw eiri, 1999):

- $\quad$ Flow relationships such as material flow, equipment, people, information and money.

- Environmental relationships such as safety, noise and temperature.

- Organizational relationships such as reporting. 
- Control relationships such as control of materials, inventory and shop floor.

Quantitative or qualitative data can be used in facility layout problems. For instance; from-to chart includes quantitative data while activity relationship diagram w orks for qualitative data. The data used in activity relationship diagram can be considered as the closeness degree. The relationships have 6 categories listed as A (Absolutely essential), E (Especially necessary), I (Important), O (Ordinary), U (Unimportant) and X (Not desirable).

We summarize the steps of the calculation of the $r_{t i k}$ closeness rates for DFLP as follows:

Step 1- Determination of input variables and fuzzification: Material flow, information flow and environmental condition are considered as input variables. The levels of material and information flow are determined as "very low, low, medium, high and very high". Alternatively, the levels are set as "very dangerless, dangerless, medium dangerous, dangerous and very dangerous" for environmental condition. On the other hand, the levels of the closeness rate which is output variables are expressed as A, E, I, O, U and X.

Step 2 - Determination of membership functions: In this step, the membership functions of the input variables are decided. The membership functions of material flow, information flow and the environmental condition are given respectively, in Figure 2, Figure 3 and Figure 4 depending on the sample data in the implementation of the study. The trapezoidal membership functions are preferred and the range of the closeness rate $(\mathrm{A}, \mathrm{E}, \mathrm{I}, \mathrm{O}, \mathrm{U}, \mathrm{X})$ is considered as $[0,6]$. Figure 5 shows the membership function of the closeness rating.

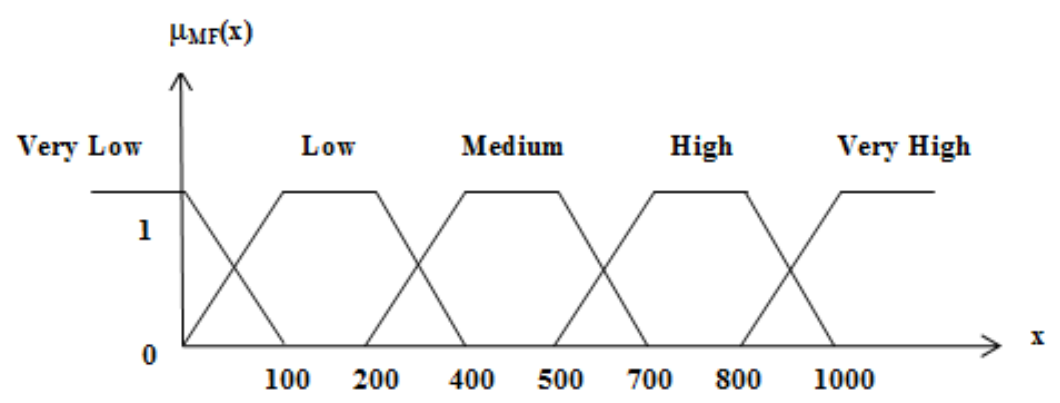

Figure 2. Membership function of material flow

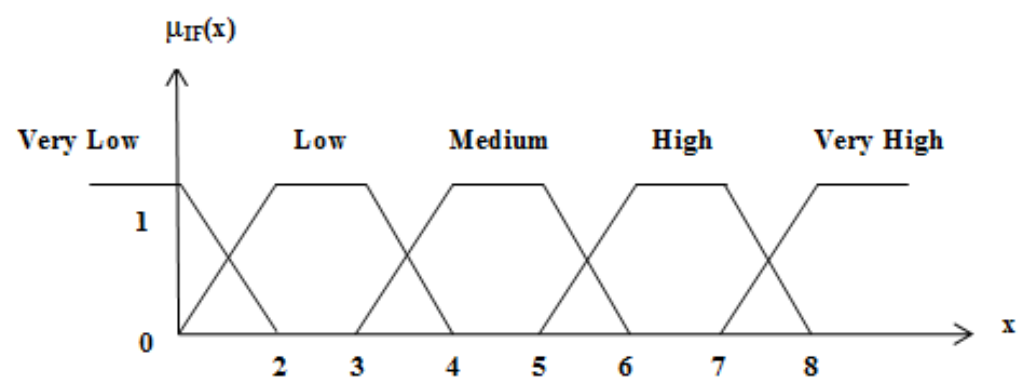

Figure 3. Membership function of information flow 


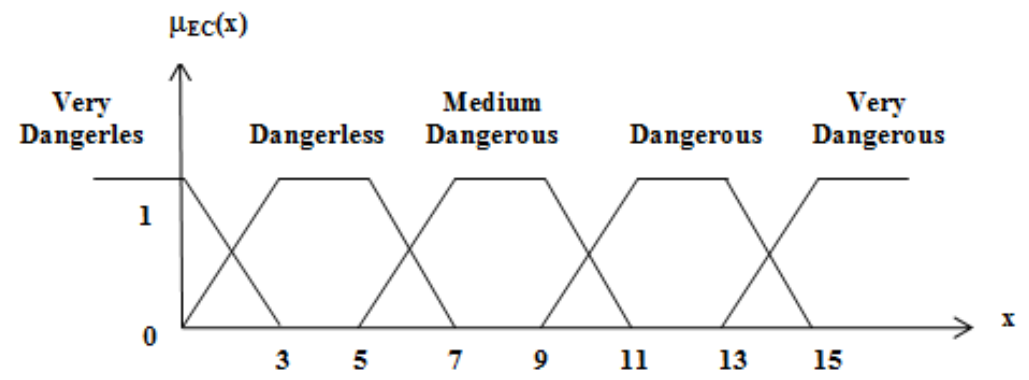

Figure 4. Membership function of environmental condition

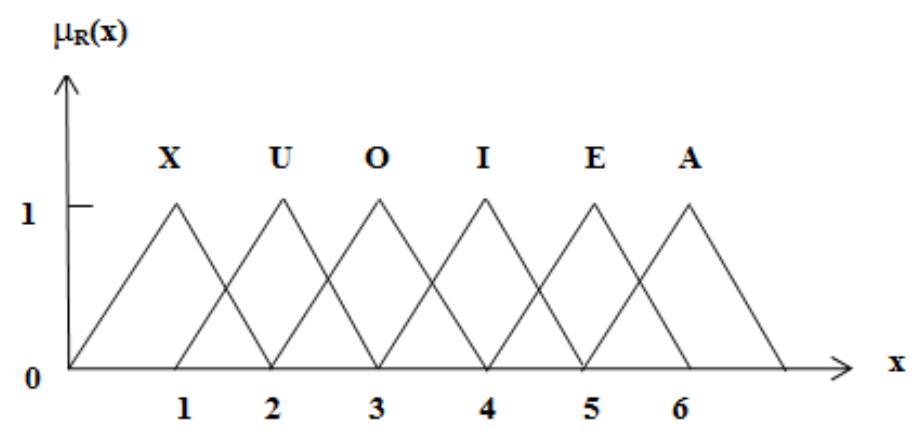

Figure 5. Membership function of closeness rating

Step 3 - The creation of fuzzy rules: In this step, Table 1, Table 2 and Table 3 are prepared to create "IFTHEN" rules between the input variables. According to these tables, a sample rule can be created as "If the material flow is medium and information flow between two departments is high, then closeness rate between these departments is E (Especially)". Tables are prepared by the experts or the decision makers who know the system well. These tables may vary depending on the type of the facility layout. The number of the rules is calculated by the following formula (Deb and Bhattacharyya, 2005):

$$
N=\sum_{j=1}^{m}\left(\prod_{i=1}^{n} L_{i}\right)
$$

$m$ : number of set of rules $(j=1,2, \ldots, m)$

$n$ : number of input variables used in each set of rules $(i=1,2, . ., n)$

$L$ : number of membership functions or levels

According to the above formula, the total number of rules is $N=5 \times 5 \times 5=125$ in this study.

Table 1. If-then rules of material flow and information flow

\begin{tabular}{|l|ccccc|}
\hline \multirow{3}{*}{ Material Flow (MF) } & \multicolumn{5}{|c|}{ Information Flow (IF) } \\
\cline { 2 - 6 } & Very Low & Low & Medium & High & Very High \\
\hline Very Low & U & U & O & O & I \\
Low & U & O & O & I & E \\
Medium & O & O & I & E & E \\
High & O & I & E & E & A \\
Very High & I & E & E & A & A \\
\hline
\end{tabular}


Table 2. If-then rules of material flow and environmental condition

\begin{tabular}{|l|ccccc|}
\hline \multirow{2}{*}{ Material Flow (MF) } & \multicolumn{5}{|c|}{ Environmental Condition (EC) } \\
\cline { 2 - 6 } & $\begin{array}{c}\text { Very } \\
\text { Dangerless }\end{array}$ & Dangerless & $\begin{array}{c}\text { Medium } \\
\text { Dangerous }\end{array}$ & Dangerous & $\begin{array}{c}\text { Very } \\
\text { Dangerous }\end{array}$ \\
\hline Very Low & $\mathrm{U}$ & $\mathrm{U}$ & $\mathrm{U}$ & $\mathrm{U}$ & $\mathrm{U}$ \\
Low & $\mathrm{O}$ & $\mathrm{O}$ & $\mathrm{U}$ & $\mathrm{U}$ & $\mathrm{X}$ \\
Medium & $\mathrm{I}$ & $\mathrm{O}$ & $\mathrm{U}$ & $\mathrm{U}$ & $\mathrm{X}$ \\
High & $\mathrm{E}$ & $\mathrm{E}$ & $\mathrm{O}$ & $\mathrm{U}$ & $\mathrm{X}$ \\
Very High & $\mathrm{A}$ & $\mathrm{A}$ & $\mathrm{I}$ & $\mathrm{O}$ & $\mathrm{X}$ \\
\hline
\end{tabular}

Table 3. If-then rules of information flow and environmental condition

\begin{tabular}{|l|ccccc|}
\hline \multirow{2}{*}{\begin{tabular}{c} 
Information Flow \\
\multicolumn{1}{|c|}{$(\mathrm{IF})$}
\end{tabular}} & \multicolumn{5}{c|}{ Environmental Condition (EC) } \\
\cline { 2 - 6 } & $\begin{array}{c}\text { Very } \\
\text { Dangerless }\end{array}$ & Dangerless & $\begin{array}{c}\text { Medium } \\
\text { Dangerous }\end{array}$ & Dangerous & $\begin{array}{c}\text { Very } \\
\text { Dangerous }\end{array}$ \\
\hline Very Low & $\mathrm{U}$ & $\mathrm{U}$ & $\mathrm{U}$ & $\mathrm{U}$ & $\mathrm{U}$ \\
Low & $\mathrm{O}$ & $\mathrm{O}$ & $\mathrm{U}$ & $\mathrm{U}$ & $\mathrm{X}$ \\
Medium & $\mathrm{I}$ & $\mathrm{O}$ & $\mathrm{U}$ & $\mathrm{U}$ & $\mathrm{X}$ \\
High & $\mathrm{E}$ & $\mathrm{I}$ & $\mathrm{U}$ & $\mathrm{U}$ & $\mathrm{X}$ \\
Very High & $\mathrm{A}$ & $\mathrm{E}$ & $\mathrm{O}$ & $\mathrm{U}$ & $\mathrm{X}$ \\
\hline
\end{tabular}

Step 4 - Defuzzification process: In this step, the defuzzification is performed to calculate the closeness rates $(r)$ between all department pairs for each period. The center of area (COA) method is chosen for the defuzzification since it is the most commonly used defuzzification method in the literature. Accordingly, the closeness rates are obtained as follows (Altaş, 1999):

$$
r=\frac{\sum_{i=1}^{N} \mu_{i}\left(r_{i}\right) \times \mathrm{r}_{i}}{\sum_{i=1}^{N} \mu_{i}\left(r_{i}\right)}
$$

where $i$ denotes the rule number and $N$ is the total number of rules. $\mu_{i}\left(r_{i}\right)$ is set to zero for inactive rules. For instance, consider that $\mathrm{MF}=232$ (Low), IF $=1$ (Low) and $\mathrm{EF}=1$ (Very dangerless) for any department pair. The active rules are created by:

- Rule 1: If the MF is low and IF is low, then the closeness rate is O (Ordinary).

- Rule 2: If the MF is low and EF is very dangerless, then the closeness rateis O (Ordinary).

- Rule 3: If the IF is low and EF is very dangerless, then the closeness rate is O (Ordinary).

The value of $\mu_{1}\left(r_{1}\right)$ for Rule 1 equal to minimum of the membership values of $\mathrm{MF}=232$ and $\mathrm{IF}=1$. In this case, it is determined as $\mu_{1}\left(r_{1}\right)=\min [0.68,0.5]=0.5$. Here, the membership value of the MF is 0.68 while the membership value of the IF is 0.5 . In the same way, it is found as $\mu_{2}\left(r_{2}\right)=0.66$ and $\mu_{3}\left(r_{3}\right)=0.5$. The closeness rate for this department pair is calculated as follows:

$$
\begin{aligned}
& r=\left[\mu\left(r_{1}\right) \times r_{1}+\mu\left(r_{2}\right) \times r_{2}+\mu\left(r_{3}\right) \times r_{3}\right] /\left[\mu\left(r_{1}\right)+\mu\left(r_{2}\right)+\mu\left(r_{3}\right)\right] \\
& r=(0.5 \times 3+0.66 \times 3+0.5 \times 3) /(0.5+0.66+0.5)=3
\end{aligned}
$$




\begin{tabular}{|l|l|l|}
\hline 1 & 2 & 3 \\
\hline 4 & 5 & 6 \\
\hline
\end{tabular}

Figure 6. Representation of the facility area

In the case study, the best layout for a dynamic layout problem with 6 departments and 5 periods is found. The material flows and relocation costs of the problem are taken from (Rosenblatt, 1986). The information flows and environmental condition data of the problem are randomly generated. The closeness rates used in the model are calculated by MATLAB. The data of the problem are given in Appendix A. GAMS mathematical modeling language is used to solve the resulting DFLP formulation. The total facility area that the departments assigned is shown in Figure 6. If the conventional closeness rates are used, the total cost turns out to be 330,727 and the layouts for each period are as given in Figure 7. On the other hand, the fuzzy system approach for the offered study is used to compute the closeness rates, the total cost is reduced to $281,901.54$ and the resulting layouts for each period are illustrated in Figure 8 . Therefore, it is seen that a $14.76 \%$ reduction in the total cost is achieved by the fuzzy system approach.

\begin{tabular}{|c|c|c|}
\hline 6 & 3 & 1 \\
\hline 5 & 4 & 2 \\
\hline
\end{tabular}

Period 1

\begin{tabular}{|l|l|l|}
\hline 6 & 3 & 1 \\
\hline 5 & 4 & 2 \\
\hline
\end{tabular}

Period 2

\begin{tabular}{|l|l|l|}
\hline 3 & 5 & 1 \\
\hline 6 & 4 & 2 \\
\hline
\end{tabular}

Period 3

\begin{tabular}{|l|l|l|}
\hline 4 & 6 & 1 \\
\hline 3 & 5 & 2 \\
\hline
\end{tabular}

Period 4

\begin{tabular}{|l|l|l|}
\hline 4 & 1 & 5 \\
\hline 3 & 2 & 6 \\
\hline
\end{tabular}

Period 5

Figure 7. Layouts based on the traditional closeness rates

\begin{tabular}{|l|l|l|}
\hline 6 & 3 & 5 \\
\hline 2 & 4 & 1 \\
\hline
\end{tabular}

Period 1

\begin{tabular}{|l|l|l|}
\hline 6 & 3 & 5 \\
\hline 2 & 4 & 1 \\
\hline
\end{tabular}

Period 2

\begin{tabular}{|l|l|l|}
\hline 6 & 4 & 3 \\
\hline 2 & 5 & 1 \\
\hline
\end{tabular}

Period 3

\begin{tabular}{|l|l|l|}
\hline 3 & 6 & 4 \\
\hline 2 & 5 & 1 \\
\hline
\end{tabular}

Period 4

\begin{tabular}{|l|l|l|}
\hline 5 & 1 & 4 \\
\hline 6 & 2 & 3 \\
\hline
\end{tabular}

Period 5

Figure 8. Layouts based on the closeness rates obtained by the fuzzy system approach 


\section{CONCLUSION}

FLP is considered to be static if the material flows don't change. How ever, production quantities can be periodically changed in today's market. This variability may be caused by the reasons such as the entry into production of new products, replacement of materials and equipment used in production, changes in the quantity demanded. As results of these, the plant layout becomes a dynamic structure. Each layout is associated with a period in the problems identified as DFLP in literature. Therefore, the total cost of a dynamic facility layout plan is the sum of material handling and reorganization costs in all periods. The reorganization costs occur when the departments are replaced to minimize the material handling costs in the transition from period to the period.

In this study, the closeness rates between departments are added to the model of DFLP as new parameters. The fuzzy system method is proposed to determine the rates. Thus, a final closeness rate is obtained by integrating several types of input variables. Also, ignored factors can be used to determine the conventional closeness rates. For an experiment, a DFLP with 6 departments and 5 periods is considered. The conventional closeness rates and the rates obtained by the fuzzy system approach in the DFLP formulation are separately used. In comparison of the results, it is seen that a $14.76 \%$ reduction in the total cost, and the different layouts are obtained.

The most important innovation of this study is to consider the environmental condition as an ergonomic factor in estimating the closeness rates with the fuzzy system approach. In the next studies, the input variable type can be increased to determine the rates, and heuristic methods can be improved to solve problems of larger size.

\section{REFERENCES}

Altaş, İ.H., 1999, “Bulanık Mantık: Bulanık denetim”, Enerji, Elektrik, Elektromekanik-3e, Vol. 64, pp. 7681.

Balakrishnan, J., Jacobs, F.R.,Venkataramanan, M.A., 1992, “Solutions for The Constrained Dynamic Facility Layout Problem", European Journal of Operational Research, Vol. 15, pp. 280-286.

Balakrishnan, J., Cheng, C.H., 1998, “Dynamic Layout Algorithms: A State-of-The-Art Survey”, Omega, Vol. 26(4), pp. 507-521.

Balakrishnan, J., Cheng, C.H., 2000, “Genetic Search and The Dynamic Layout Problem”, Computers and Operations Research, Vol.27(6), pp.587-593.

Balakrishnan, J., Cheng, C.H., Conway, D.G., Lau, C.M., 2003, “A Hybrid Genetic Algorithm For The Dynamic Plant Layout Problem", International Journal of Production Economics, Vol. 86, pp. 107120.

Baykasoğlu, A., Gindy, N.N.Z., 2001, “A Simulated Annealing Algorithm for Dynamic Layout Problem”, Computers and Operations Research, Vol. 28, pp. 1403-1426.

Baykasoglu, A., Dereli, T., Sabuncu, I., 2006, “An Ant Colony Algorithm for Solving Budget Constrained and Unconstrained Dynamic Facility Layout Problems", Omega-International Journal of Management Science, Vol.34(4), pp. 385-396.

Benlic, U., Hao, J-K., 2013, "Break Local Search for The Quadratic Assignment Problem", Applied Mathematics and Computation, Vol. 219(9), pp. 4800-4815.

Conway, D.G., Venkataramanan, M.A., 1994, "Genetic Search and The Dynamic Facility Layout Problem", Computers and Operations Research, Vol. 21(8), pp. 955-960.

Deb, S.K., Bhattacharyya, B., 2005, “Fuzzy Decision Support System for Manufacturing Facilities Layout Planning", Decision Support Systems, Vol.40, pp. 305-314.

Dweiri, F., 1999, "Fuzzy Development of Crisp Activity Relationship Charts for Facilities Layout", Computers E Industrial Engineering, Vol. 36, pp.1-16.

El-Rayes, K., Said, H., 2009, Dynamic Site Layout Planning Using Approximate Dynamic Programming, Journal of Computing in Civil Engineering, Vol. 23(2), pp. 119-127. 
Erel, E., Ghosh, J.B., Simon, J.T., 2003, “New Heuristic for The Dynamic Layout Problem”, Journal of the Operational Research Society, Vol. 54, pp. 1275-1282.

Fortenberry, J.F., Cox, J.S., 1985, "Multiple Criteria Approach to The Facilities Layout Problem", International Journal of Production Research, Vol. 23(4), pp.773-782.

GrobeIny, J., 1987a, "The Fuzzy Approach to Facility Layout Problems", Fuzzy Sets and Systems, Vol. 23, pp. $175-190$.

GrobeIny, J., 1987b, “On One Possible Fuzzy Approach to Facility Layout Problems”, International Journal of Production Research, Vol.25, pp. 1123-1141.

Grobelny, J., 1988, “The 'Linguistic Pattern' Method for A Work Station Layout Analysis”, International Journal of Production Research, Vol. 26, pp. 1779-1798.

Hirabayashi, N., Kita, H., Nagasawa, H., 1999, "Dynamic Facility Layout Using Evolution Strategies", Proceedings of the Second World Manufacturing Congress, 154-159.

Hosseini, S., Al Khaled, A., Vadlamani, S., 2014, “Hybrid Imperialist Competitive Algorithm,Variable Neighborhood Search, and Simulated Annealing for Dynamic Facilitylayout Problem", Neural Computing and Applications, Vol. 25, pp.1871-1885.

Kaku, B.K., Mazzola, J.B., 1997, “A Tabu-Search Heuristic for The Dynamic Plant Layout Problem”, INFORMS Journal on Computing, Vol. 9(4), pp. 374-384.

Koopmans, T.C., Beckmann, M.J., 1957, “Assignment Problems and The Location of Economic Activities", Econometrica, Vol. 25, pp. 53-76.

Lacksonen, T.A., Enscore, E.E., 1993, "Quadratic Assignment Algorithms for The Dynamic Layout Problem", International Journal of Production Research, Vol. 31(3), pp. 503-517.

Mazinani, M., Abedzadeh, M., Mohebali, N., 2013, “Dynamic Facility Layout Problem Basedon Flexible Bay Structure and Solving by Genetic Algorithm", International Journal of Advanced Manufacturing Technology, Vol. 65, pp. 929-943.

McKendall, A.R., Shang, J., 2006, "Hybrid Ant Systems for The Dynamic Facility Layout Problem", Computers \& Operations Research, Vol. 33(3), pp. 790-803.

McKendall, A.R., Liu, W.H., 2012, "New Tabu Search Heuristics for The Dynamic Facility Layout Problem", International Journal of Production Research., Vol. 50(3), pp.867-78.

Moslemipour, G., Lee, T.S., Rilling, D., 2012, “A Review of Intelligent Approaches for Design-Ing Dynamic and Robust Layouts in Flexible Manufacturing Systems", International Journal of Advanced Manufacturing Technology, Vol. 60, pp. 11-27.

Nourelfath, M., Nahas, N. Montreuil, B., 2007, “Coupling Ant Colony Optimization and The Extended Great Deluge Algortihm for The Discrete Facility Layout Problem", Engineering Optimization, Vol. 39(8), pp. 953-998.

Pourvaziri, H., Naderi, B., 2014, “A Hybrid Multi-Population Genetic Algorithm for The Dynamic Facilitylayout Problem", Applied Soft Computing, Vol. 24, pp. 457-469.

Rosenblatt, M.J., 1986, “The Dynamics of Plant Layout”, Management Science, Vol. 32(1), pp. 76-86.

Raoot, A.D., Rakshit, A., 1991, "A Fuzzy Approach to Facilities Layout Planning", International Journal of Production Research, Vol. 29, pp. 835-857.

Raoot, A.D., Rakshit, A., 1993, “A `Linguistic Pattern' Approach for Multiple Criteria Facility Layout Problems", International Journal of Production Research, Vol.31, pp. 203-222.

Sahin, R., Ertogral, K., Turkbey, O., 2010, “A Simulated Annealing Heuristic for The Dynamic Layout Problem with Budget Constraint", Computers \& Industrial Engineering, Vol. 59, pp. 308-13.

Sahni, S., Gonzales, T., 1976, "P-Complete Approximation Problems", Journal of the Association for Computing Machinery, Vol. 23, pp. 555-565.

Şen, Z. 2001, Bulanık Mantık ve Modelleme İlkeleri, Bilge Yayıncılık, İstanbul.

Ulutaş, H.B., Islier, A.A., 2009, "A Clonal Selection Algorithm for Dynamic Facility Layout Problems", Journal of Manufacturing Systems, Vol. 28(4), pp. 123-131.

Ulutaş, B., Islier, A.A., 2015, "Dynamic Facility Layout Problem in Footwear Industry", Journal of Manufacturing Systems, Vol.36, pp. 55-61. 
Wilhelm, M.R., Karwowski, W., Evans G.W., 1987, "A Fuzzy Set Approach to Layout Analysis", International Journal of Production Research, Vol. 25, pp. 1431-1450.

Zadeh, L.A. , 1965, "Fuzzy Sets", Information and Control, Vol. 8, pp. 338-353.

Zouein, P.P., Tommelein, I.D., 1999, “Dynamic Layout Planning Using A Hybrid Incremental Solution Method", Journal of Construction Engineering and Management, Vol. 125(6), pp. 400-408. 
UNIVERSITESI

MÜHENDİSLIK FAKÜLTESI

\begin{tabular}{|c|c|c|c|c|c|c|c|c|c|c|c|c|c|c|c|c|c|c|c|c|c|c|c|c|c|c|c|c|c|c|c|}
\hline & & \multicolumn{6}{|c|}{ Material flow } & \multicolumn{6}{|c|}{ Information flow } & \multicolumn{6}{|c|}{ Environmental condition } & \multicolumn{6}{|c|}{ Traditional closeness rates } & \multicolumn{6}{|c|}{ Closeness rates obtained by the proposed method } \\
\hline & & 1 & 2 & 3 & 1 & 5 & 6 & 1 & 2 & 3 & 4 & 5 & 6 & 1 & 2 & 3 & 4 & 5 & 6 & 1 & 2 & 3 & 4 & 5 & 6 & 1 & 2 & 3 & 4 & 5 & 6 \\
\hline \multirow{6}{*}{ 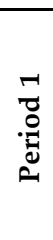 } & 1 & 0 & 63 & 605 & 551 & 116 & 136 & 0 & 1 & 4 & 4 & 3 & 2 & 0 & 1 & 2 & 2 & 1 & 3 & 0 & 3 & 5 & 5 & 3 & 3 & 0 & 3 & 4.33 & 4.27 & 3 & 3 \\
\hline & 2 & 63 & 0 & 635 & 941 & 50 & 191 & 1 & 0 & 3 & 7 & 1 & 1 & 1 & 0 & 5 & 7 & 2 & 2 & 3 & 0 & 5 & 6 & 3 & 3 & 3 & 0 & 4 & 4 & 3 & 3 \\
\hline & 3 & 104 & 71 & 0 & 569 & 136 & 55 & 4 & 3 & 0 & 8 & 5 & 4 & 2 & 5 & 0 & 4 & 1 & 1 & 5 & 5 & 0 & 6 & 5 & 5 & 4.43 & 4 & 0 & 6 & 4.72 & 4.72 \\
\hline & 4 & 65 & 193 & 622 & 0 & 77 & 90 & 4 & 7 & 8 & 0 & 2 & 4 & 2 & 7 & 4 & 0 & 11 & 6 & 5 & 6 & 6 & 0 & 5 & 5 & 4.27 & 4 & 6 & 0 & 2.62 & 3.75 \\
\hline & 5 & 162 & 174 & 607 & 591 & 0 & 179 & 3 & 1 & 5 & 2 & 0 & 2 & 1 & 2 & 1 & 11 & 0 & 1 & 3 & 3 & 5 & 5 & 0 & 4 & 3 & 3 & 4.72 & 2.62 & 0 & 3.32 \\
\hline & 6 & 156 & 13 & 667 & 611 & 175 & 0 & 2 & 1 & 4 & 4 & 2 & 0 & 3 & 2 & 1 & 6 & 1 & 0 & 3 & 3 & 5 & 5 & 4 & 0 & 3 & 3 & 4.72 & 3.75 & 3.32 & 0 \\
\hline \multirow{6}{*}{ 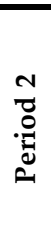 } & $\overline{1}$ & 0 & 175 & 804 & 904 & 56 & 176 & 0 & 5 & 3 & 3 & 1 & 2 & 0 & 2 & 2 & 3 & 1 & 3 & 0 & 3 & 6 & 6 & 3 & 3 & 0 & 3 & 4.7 & 4.52 & 3 & 3 \\
\hline & 2 & 63 & 0 & 743 & 936 & 45 & 177 & 5 & 0 & 4 & 4 & 3 & 3 & 2 & 0 & 4 & 8 & 3 & 2 & 3 & 0 & 5 & 6 & 3 & 3 & 3 & 0 & 5 & 5 & 3 & 3 \\
\hline & 3 & 168 & 85 & 0 & 918 & 138 & 134 & 3 & 4 & 0 & 8 & 5 & 6 & 2 & 4 & 0 & 3 & 2 & 3 & 6 & 5 & 0 & 6 & 5 & 6 & 4.7 & 5 & 0 & 5.67 & 4.33 & 5.33 \\
\hline & 4 & 51 & 94 & 962 & 0 & 173 & 39 & 3 & 4 & 8 & 0 & 4 & 3 & 3 & 8 & 3 & 0 & 9 & 7 & 6 & 6 & 6 & 0 & 5 & 5 & 4.52 & 5 & 5.67 & 0 & 3.32 & 2.86 \\
\hline & 5 & 97 & 104 & 730 & 634 & 0 & 144 & 1 & 3 & 5 & 4 & 0 & 4 & 1 & 3 & 2 & 9 & 0 & 2 & 3 & 3 & 5 & 5 & 0 & 3 & 3 & 3 & 4.33 & 3.32 & 0 & 3 \\
\hline & 6 & 95 & 115 & 983 & 597 & 24 & 0 & 2 & 3 & 6 & 3 & 4 & 0 & 3 & 2 & 3 & 7 & 2 & 0 & 3 & 3 & 6 & 5 & 3 & 0 & 3 & 3 & 5.33 & 2.86 & 3 & 0 \\
\hline \multirow{6}{*}{ 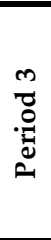 } & 1 & 0 & 90 & 77 & 553 & 769 & 139 & 0 & 5 & 1 & 3 & 6 & 2 & 0 & 13 & 2 & 1 & 3 & 1 & 0 & 3 & 3 & 4 & 6 & 3 & 0 & 2.29 & 3 & 3.32 & 5.24 & 3 \\
\hline & 2 & 168 & 0 & 114 & 653 & 525 & 185 & 5 & 0 & 3 & 5 & 6 & 2 & 13 & 0 & 4 & 7 & 3 & 2 & 3 & 0 & 3 & 5 & 4 & 4 & 2.29 & 0 & 3 & 3.29 & 4 & 3 \\
\hline & 3 & 32 & 35 & 0 & 664 & 898 & 87 & 1 & 3 & 0 & 6 & 5 & 4 & 2 & 4 & 0 & 1 & 2 & 1 & 3 & 3 & 0 & 5 & 6 & 3 & 3 & 3 & 0 & 5 & 4.67 & 3.33 \\
\hline & 4 & 27 & 166 & 42 & 0 & 960 & 179 & 3 & 5 & 6 & 0 & 5 & 3 & 1 & 7 & 1 & 0 & 7 & 5 & 4 & 5 & 5 & 0 & 6 & 5 & 3.32 & 3.29 & 5 & 0 & 3.67 & 3.98 \\
\hline & 5 & 185 & 56 & 44 & 926 & 0 & 104 & 6 & 6 & 5 & 5 & 0 & 5 & 3 & 3 & 2 & 7 & 0 & 1 & 6 & 4 & 6 & 6 & 0 & 5 & 5.54 & 4 & 4.67 & 3.67 & 0 & 4.72 \\
\hline & 6 & 72 & 128 & 173 & 634 & 687 & 0 & 2 & 2 & 4 & 3 & 5 & 0 & 1 & 2 & 1 & 5 & 1 & 0 & 3 & 4 & 3 & 5 & 5 & 0 & 3 & 3 & 3.33 & 3.98 & 4.72 & 0 \\
\hline \multirow{6}{*}{$\begin{array}{l}+1 \\
\square \\
0 \\
0 \\
0 \\
0\end{array}$} & 1 & 0 & 112 & 15 & 199 & 665 & 649 & 0 & 4 & $\overline{1}$ & 3 & 6 & 5 & $\overline{0}$ & 2 & $\overline{1}$ & 2 & 1 & 3 & 0 & 3 & 2 & 3 & 5 & 5 & $\overline{0}$ & 3 & 2.3 & 3 & 5 & 4.33 \\
\hline & 2 & 153 & 0 & 116 & 173 & 912 & 671 & 4 & 0 & 2 & 3 & 7 & 5 & 2 & 0 & 3 & 6 & 2 & 2 & 3 & 0 & 3 & 3 & 6 & 5 & 3 & 0 & 3 & 2.44 & 5.4 & 4.43 \\
\hline & 3 & 10 & 28 & 0 & 182 & 855 & 542 & 1 & 2 & 0 & 1 & 2 & 4 & 1 & 3 & 0 & 4 & 1 & 2 & 2 & 3 & 0 & 3 & 4 & 5 & 2.3 & 3 & 0 & 3 & 3.91 & 4.43 \\
\hline & 4 & 29 & 69 & 15 & 0 & 552 & 751 & 3 & 3 & 1 & 0 & 5 & 6 & 2 & 6 & 4 & 0 & 7 & 6 & 3 & 3 & 3 & 0 & 4 & 5 & 3 & 2.44 & 3 & 0 & 2.55 & 3.6 \\
\hline & 5 & 198 & 71 & 42 & 24 & 0 & 758 & 6 & 7 & 2 & 5 & 0 & 7 & 1 & 2 & 1 & 7 & 0 & 3 & 5 & 6 & 4 & 4 & 0 & 6 & 5 & 5.4 & 3.91 & 2.55 & 0 & 5.33 \\
\hline & 6 & 62 & 109 & 170 & 90 & 973 & 0 & 5 & 5 & 4 & 6 & 7 & 0 & 3 & 2 & 2 & 6 & 3 & 0 & 5 & 5 & 5 & 5 & 6 & 0 & 4.33 & 4.43 & 4.43 & 3.6 & 5.33 & 0 \\
\hline \multirow{6}{*}{ 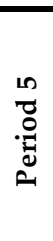 } & 1 & 0 & 663 & 23 & 128 & 119 & 50 & 0 & 7 & 6 & 4 & 8 & 4 & $\overline{0}$ & 11 & 3 & 3 & 2 & $\overline{1}$ & $\overline{0}$ & 6 & 5 & 6 & 6 & 5 & $\overline{0}$ & 3.67 & 4.6 & 4.52 & 5.72 & 4.69 \\
\hline & 2 & 820 & 0 & 5 & 98 & 141 & 66 & 7 & 0 & 3 & 3 & 4 & 4 & 11 & 0 & 5 & 8 & 4 & 1 & 6 & 0 & 5 & 5 & 5 & 5 & 3.67 & 0 & 3.91 & 4 & 5 & 4.72 \\
\hline & 3 & 822 & 650 & 0 & 137 & 78 & 91 & 6 & 3 & 0 & 5 & 4 & 3 & 3 & 5 & 0 & 3 & 2 & 2 & 5 & 5 & 0 & 3 & 3 & 3 & 4.6 & 3.91 & 0 & 3 & 3 & 3 \\
\hline & 4 & 826 & 570 & 149 & 0 & 93 & 151 & 4 & 3 & 5 & 0 & 2 & 1 & 3 & 8 & 3 & 0 & 9 & 3 & 6 & 5 & 3 & 0 & 3 & 3 & 4.52 & 4 & 3 & 0 & 2.33 & 3 \\
\hline & 5 & 915 & 515 & 53 & 35 & 0 & 177 & 8 & 4 & 4 & 2 & 0 & 1 & 2 & 4 & 2 & 9 & 0 & 1 & 6 & 5 & 3 & 3 & 0 & 3 & 5.72 & 5 & 3 & 2.33 & 0 & 3 \\
\hline & 6 & 614 & 729 & 178 & 10 & 99 & 0 & 4 & 4 & 3 & 1 & 1 & 0 & 1 & 1 & 2 & 3 & 1 & 0 & 5 & 5 & 3 & 3 & 3 & 0 & 4.69 & 4.72 & 3 & 3 & 3 & 0 \\
\hline
\end{tabular}

\begin{tabular}{|l|l|l|l|l|l|l|}
\hline Re-layout costs & 887 & 964 & 213 & 367 & 289 & 477 \\
\hline
\end{tabular} 